\title{
Electrochemistry and Spectroscopy Study on Nitrate Reduction Catalyzed by Iron and Cobalt Protoporphyrin Immobilized Pyrolytic Graphite
}

\author{
Jing Shen*, Kaiming Xiang, Donghui Lan*, Zequn Miu, Zhengjun Fang, Jia Wang, \\ Ganluo Xiao, Heng Xiao \\ Hunan Provincial Key Laboratory of Environmental Catalysis \& Waste Recycling, School of Material \\ and Chemical Engineering, Hunan Institute of Engineering, Xiangtan, 411104, P.R. China. \\ *E-mail: jingshen84@sina.com ; donghuilan@ @nu.edu.cn
}

doi: $10.20964 / 2020.08 .20$

Received: 31 March 2020 / Accepted: 6 May 2020 / Published: 10 July 2020

\begin{abstract}
The nitrogen-cycle is one of the most important material cycles in bioshpere. With the high nitrate concentration in ground water, it is important to find methods to reduce its content. Otherwise, it will be harmful for human healthy. The electrochemical reduction of nitrate is an effective technique to accomplish the goal. With iron and cobalt protoporphyrins acting as heterogenous catalyst, the nitrate ions have been reduced to hydroxylamine and ammonia efficiently. The process is highly dependent on $\mathrm{pH}$ as the real active reactant of the reaction is $\mathrm{NO}$ which comes from the disproportionation reaction of nitrite and also nitrate concentration. The detailed investigations on the influence of $\mathrm{pH}$ and nitrate concentration on the electrochemical reduction of nitrate on cobalt protoporphyrin illustrate that the formation of ammonia probably goes through two different pathways, one of which is a direct pathway without going through hydroxylamine and the other is a sequential pathway which is from hydroxylamine reduction. FTIR spectra confirm that the most valuable intermediate of the reaction is adsorbed HNO (M-HNO).
\end{abstract}

Keywords: Nitrate reduction; $\mathrm{pH}$ dependent; NO; M-HNO

\section{FULL TEXT}

(C) 2020 The Authors. Published by ESG (www.electrochemsci.org). This article is an open access article distributed under the terms and conditions of the Creative Commons Attribution license (http://creativecommons.org/licenses/by/4.0/). 